\title{
APPLICATION OF FLOW-THROUGH THREE-DIMENSIONAL ELECTRODES FOR REGENERATION OF PLATING IRON ELECTROLYTES: 2. STUDY OF PROCESS REGULARITIES BY MATHEMATICAL MODELING
}

\author{
Olga Covaliova ${ }^{\mathrm{a}^{*}}$, Alexandr Koshev ${ }^{\mathrm{b}}$, Valery Varentsov ${ }^{\mathrm{c}}$ \\ ${ }^{a}$ State University of Moldova, Research Center of Applied and Ecological Chemistry, 60, A. Mateevici str., \\ Chisinau MD 2009, Republic of Moldova \\ ${ }^{b}$ Penza State University of Architecture and Construction, 28, G.Titova str., Penza 440028, Russian Federation \\ 'Institute of Solid and Mechanochemistry of the Siberian Branch of RAS, 18, Kutateladze str., \\ Novosibirsk 630128, Russian Federation \\ *e-mail: covaleva.olga@yahoo.com; phone/fax: (+373 22) 577556
}

\begin{abstract}
The main regularities of the electroactive components distribution, polarization and local current density within the depth of the three-dimensional flow-through electrode have been studied using the calculation method, in dependence on the overall current density, electrode thickness and degree of its compression, solution flow velocity through the electrode, initial concentration of Fe(III) ions in the solution and electrodes brand.
\end{abstract}

Keywords: three-dimensional flow-through electrode, mathematical modeling, numerical calculations, polarization, local current density.

\section{Introduction}

Mathematical modeling [1,2] is one of the efficient methods allowing to research the regularities of the flowthrough three-dimensional electrodes operation, including those made of the carbon fibrous materials (CFM). It makes it possible to study the processes occurring within the bulk such electrodes. In addition, this method offers a possibility to predict the effect of the main technological parameters on the studied process and to optimize the electrolysis conditions.

The mathematical model is based on the solution of the system of equations [3], which describe the distribution of the reacting substances concentration, polarization and current inside the pores of the three-dimensional electrode, and involve a series of parameters, which are partly known from the literature data (reaction equilibrium potentials, masstransfer and diffusion coefficients, amount of electrons transmitted during the reaction). Another part of parameters, among which the characteristics of CFM electrodes, their reaction surface, porosity $[4,5]$ can be determined by the experimental methods.

The analytical resolving of the differential equations system is usually difficult and is limited by consideration of some particular cases only. Therefore, in our research the numerical computational calculations were carried out, which results made it possible to reveal the regularities of the processes running within the bulk of carbon fibrous electrodes (CFE) during the electrochemical regeneration of iron plating solutions.

\section{Method and conditions of the numerical calculations at the modeling of electrolysis on CFE}

During the occurrence of the processes on CFE, the principal mass and charge transfer takes place by the forced convection, when the diffusion and natural convection are negligibly low. Then, according to the mathematical description given in [6], the process of $n$ components reduction within the bulk of porous electrode is described by the following Eq.:

$$
j_{i}(X)=\frac{j_{i 0}\left[e^{M_{i 1}}-e^{M_{i 2}}\right]}{1+j_{i 0} e^{M_{i 1}} / z_{i} F C_{i}(x) v(x)},
$$

where $j_{i o}$ - exchange current density; $j_{i}$ - polarizing current density; $z_{i}$ - charge of $i$-th electroactive component $(i=1, \ldots, 4)$; $F$ - Faraday's number, $C \mathrm{~mol}^{-1} ; D$ - diffusion coefficient, $\mathrm{cm}^{2} / \mathrm{s} ; C_{i}(x)$ - concentration of $i$-th electroactive component $(i=1, \ldots, 4) ; v(x)$ - velocity vector of the convection transfer of electrolyte along the axes or linear velocity of electrolyte flow,

$$
\begin{aligned}
M_{i 1} & =\frac{\alpha_{i} z_{i} F\left(E(x)-E_{i p}(x)\right)}{R T} \\
M_{i 2} & =\frac{\left(1-\alpha_{i}\right) z_{i} F\left(E(x)-E_{i p}(x)\right)}{R T} .
\end{aligned}
$$

Here $E(x)$ and $E_{i p}(x)$ is a potential and equilibrium potential for $i$-th component in a point "x", accordingly.

Presented at the International Conference dedicated to the $55^{\text {th }}$ anniversary from the foundation of the Institute of Chemistry of the Academy of Sciences of Moldova 
Eq.(1) can be presented in another form, once the value $j_{i, \text { limi }}(x)=\frac{z_{i} F D_{i} C_{i x}}{r_{\theta}}$ is introduced in consideration, which in the first approximation reflects the value of limited diffusion density:

$$
j_{i}(x)=\frac{P e_{i} j_{0}\left[e^{M_{i 1}}-e^{M_{i 2}}\right]}{P e_{i}+j_{i 0} e^{M_{i 1}} / j_{i, \text { lim }}(x)}
$$

where $P e_{i}-$ Peclet number for $i$-th electroactive component.

As it was mentioned earlier, to perform the numerical calculations according to the mathematical model involved, it is necessary to know the values of certain physical and kinetic factors, characterizing the studied system, in which the following reactions can take place: $\mathrm{Fe}(\mathrm{III}) \stackrel{+e}{\longrightarrow} \mathrm{Fe}(\mathrm{II}) ; \mathrm{Fe}(\mathrm{II}) \stackrel{+2 e}{\longrightarrow} \mathrm{Fe}^{0} ; 2 \mathrm{H}^{+} \rightarrow \mathrm{H}_{2}$.

The calculations were performed with regard to the electrolyte, broadly used in practical applications, containing $\mathrm{Fe}(\mathrm{II})$ ions $\left(0.5 \cdot 10^{-3} \mathrm{~mol} / \mathrm{L}\right)$ and $\mathrm{Fe}(\mathrm{III})$ ions $\left(0.5 \cdot 10^{-4} \mathrm{~mol} / \mathrm{L}\right)$. The measured value of the solution electroconductivity made $\mathrm{c}_{1}=0.14 \Omega / \mathrm{cm}$. As cathodes, the CFM types VINN-250 (BИHH-250), NTM-100 (HTM-100), NTM-200 (HTM200), VVP-66-95 (ВВП-66-95), KNM (КНM), VNG-50 (ВНГ-50), TGN (ТГН) and TVS (ТВШ) were used, for which the known parameters were taken: specific reaction surface $\left(\mathrm{S}_{\mathrm{v}}, \mathrm{cm}^{2} / \mathrm{cm}^{3}\right)$, electrode electroconductivity $(\mathrm{c}, \Omega / \mathrm{cm})$ and electrode material porosity (Î) $[5,6]$, and their change with the 2 -fold compression was taken in consideration. Such parameters as current density $\left(\mathrm{j}, \mathrm{A} / \mathrm{cm}^{2}\right)$ and linear flow velocity $(\mathrm{u}, \mathrm{cm} / \mathrm{s})$ were varied within the defined limits for obtaining of the appropriate dependencies.

For the reaction $\mathrm{Fe}(\mathrm{III}) \stackrel{+e}{\longrightarrow} \mathrm{Fe}(\mathrm{II})$ the diffusion coefficient $D^{\mathrm{Fe}(\mathrm{II})}$ and exchange current $\mathrm{j}_{0}$ of $\mathrm{Fe}$ (II) ions determined from the data of our polarization studies [7, 8], made, accordingly, $0.535 \cdot 10^{-5} \mathrm{~cm} / \mathrm{s}$ and $0.019 \mathrm{~A} / \mathrm{cm}^{2}$. According to the same studies results, the stationery potential of the reaction considered makes $E^{\mathrm{Fe}(I I I)}=+0.643 \mathrm{~V}$. The amount of electrons during the transfer of $\mathrm{Fe}(\mathrm{III})$ into $\mathrm{Fe}(\mathrm{II})$ is 1, and the transfer coefficient of Fe(III) ions, according to [9], is equal to 0.59 .

For the reaction of metal iron reducing $\mathrm{Fe}(\mathrm{II}) \stackrel{+2 e}{\longrightarrow} \mathrm{Fe}^{0}$, the kinetic parameters are: $D^{\mathrm{Fe}(\mathrm{II})}=0.6 \cdot 10^{-5} \mathrm{~cm} / \mathrm{s}[9]$; $\mathrm{a}^{\mathrm{Fe}(\mathrm{II})}=0.43[9] ; z^{\mathrm{Fe}(\mathrm{II})}=2$. The value of stationery potential $E^{\mathrm{Fe}(\mathrm{II})}=-0.620 \mathrm{~V}$ was determined during the polarization studies on the graphite surface [7]. As to the exchange current of $\mathrm{Fe}$ (II) ions ( $j_{o}$ Fe(II), for the process limited by the charge transfer stage it was necessary to consider the increase of its value, due to the high CFE surface with the fibers micro-

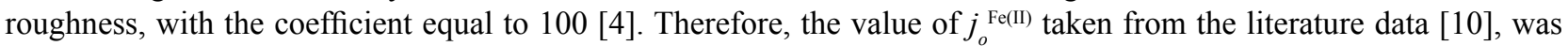
considered to be 2 orders higher and made $1 \cdot 10^{-6} \mathrm{~A} / \mathrm{cm}^{2}$.

For the third of possible reactions in the studied system - hydrogen emission, the kinetic parameters were taken as follows: $E^{H_{2}}$, according to the polarization studies on the graphite surface [7], made - $0.83 \mathrm{~V}$; transfer coefficient was $\alpha^{H_{2}}=0.49$ [9]. The exchange current was calculated considering the aforementioned correction with regard to the data $[10]$ and made $j_{o} H_{2}=2 \cdot 10^{-6} \mathrm{~A} / \mathrm{cm}^{2}$.

Therefore, the processes taken place on the CFE during the electrochemical regeneration of iron plating solution, are accompanied with the formation of the products in the ionic $(\mathrm{Fe}(\mathrm{II}))$ or gaseous state $\left(\mathrm{H}_{2}\right)$. However, as it was shown [7], with the polarization increase, the electrode potential is shifted to the electronegative field, reaching the values, at which the metal iron is deposited.

It was earlier shown that the presence of oxygen, the reduction-oxidation system is formed in the iron electrolyte, which under the dynamic conditions causes the rapid oxidation of Fe(III) ions to $\mathrm{Fe}(\mathrm{II})$ [11]. Our polarization studies has shown [8], that the dependence the of limiting diffusion current value of the reaction $\mathrm{Fe}(\mathrm{III}) \stackrel{+e}{\longrightarrow} \mathrm{Fe}$ (II) from the $\mathrm{Fe}(\mathrm{III})$ ions concentration is a straight line, which do not pass through the origin of coordinates, but clipping/cutting of a certain segment on the currents' axis, which may correspond to the current consumed for the reduction of oxygen. (Once the oxygen is removed from the electrolyte solution by the blowing of inert gas, the analogous straight line passes through the origin of coordinates). It is possible that a part of dissolved oxygen which did not react with $\mathrm{Fe}(\mathrm{III})$ ions, is involved in this reaction.

Thus, in our calculations we have considered possible electrochemical evolving of oxygen dissolved in water [12]. For the studied process it was supposed that the following electrode reaction with oxygen participation occurs, in which the intermediate product is the adsorbed oxygen atom:

$\mathrm{O}_{2} \rightarrow 2 \mathrm{O}_{\text {ads. }} ; \mathrm{O}_{\text {ads. }}+2 \mathrm{H}^{\cdot}+2 \mathrm{e} \rightarrow \mathrm{H}_{2} \mathrm{O}$.

The mechanism of this reaction was studied by A.N. Frumkin [13] with regard to the carbon electrodes, possessing high adsorption properties. For this reaction the kinetic parameters are as follows: $E_{P}^{O_{2}}=1.1 \mathrm{~V} ; j_{0}^{O_{2}}=10^{-8}$ $\mathrm{A} / \mathrm{cm}^{2} ; \mathrm{z}^{\mathrm{O}_{2}}=2$ [14]. Oxygen concentration was thus taken to be equal to its solubility in water ( $\mathrm{T}=295 \mathrm{~K}$ ), which makes $\mathrm{C}_{0}^{O_{2}}=2 \cdot 10^{-4} \mathrm{~mol} / \mathrm{L}[14]$.

The calculations were made in the conditions of uniflow system, i.e. for the one-time pass of the treated solution through the electrode. 
The results were received in the numerical form, and on their base the graphs have been created, reflecting the regularities of the electrolysis processes on CFE. Further, the calculated values were compared to the experimental data in order to estimate their convergence.

\section{The results of numerical calculations and their discussions Effect of current density}

Current density is one of the main technological parameters which allow ensuring the high efficiency of electrochemical process on CFE. The data obtained by the calculation method (Figure 1) demonstrate that with the increase of the overall current density to $1000 \mathrm{~A} / \mathrm{m}^{2}$ the process rate increases sharply and then is stabilized on a certain level. At the same time, the current efficiency of the target reaction $\mathrm{Fe}(\mathrm{III}) \stackrel{+e}{\longrightarrow} \mathrm{Fe}(\mathrm{II})$, starting with these current densities, is decreasing. Such character of the dependencies indicates that equally with the target reaction, the secondary ones occur, resulting in the evolving of hydrogen and depositing of metal iron.

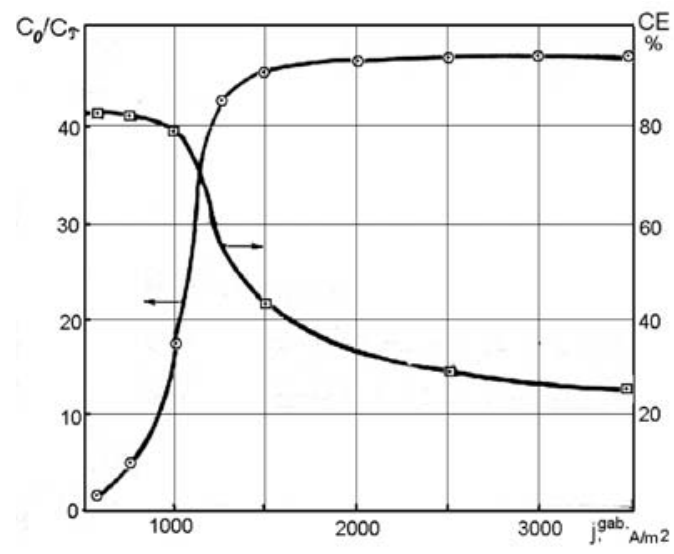

Figure 1. Dependence of the rate of electrochemical reductions of $\mathrm{Fe}$ (III) ions to $\mathrm{Fe}$ (II) and current efficiency on the current density.

Conditions: electrode material VINN-250; $\mathrm{S}_{\mathrm{v}}=560 \mathrm{~cm}^{2} / \mathrm{g} ; \in=0.925$

$\chi_{S}=0.4 \Omega / \mathrm{cm} ; L=0.1 \mathrm{~cm} ; \mathbf{u}=0.1 \mathrm{~mL} / \mathrm{s}$; $\mathrm{C}_{\text {initial }} \mathrm{Fe(III)}=\mathbf{8 . 9} \cdot 10^{-3} \mathrm{~mol} / \mathrm{L}$.

The work of CFE under the conditions of the solution flow is connected with the non-uniform distribution of the reacting substances concentration within the electrode depth that is testified by the data on Figure 2.

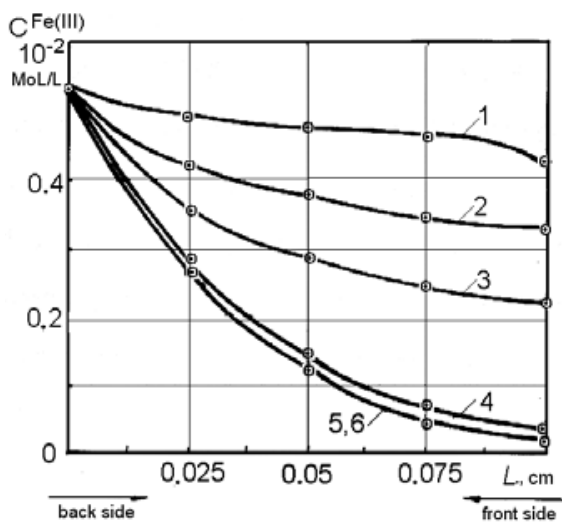

Figure 2. Distribution of ions Fe(III) concentration along the depth of TDE in dependence on current density, $\mathbf{A} / \mathbf{m}^{2}$ :

$1-200 ; 2-300 ; 3-500 ; 4-1000 ; 6-1500$ and 2000 , accordingly.

The conditions are the same as related to Figure 1.

The polarization distribution of reaction $\mathrm{Fe}(\mathrm{III}) \stackrel{+e}{\longrightarrow} \mathrm{Fe}(\mathrm{II})$ shown in Figure 3A demonstrates that under the low overall current densities for the low depth electrode, there is an uniform decrease in this value from the back side of the electrode towards the front one. With the increase in $\mathrm{j}_{\mathrm{K}}{ }^{\text {overall }}$ appears the polarization minimum, which shifts towards the front side. The calculations show that at the $\mathrm{j}_{\mathrm{K}} \approx 1200 \mathrm{~A} / \mathrm{m}^{2}$ the limiting current is reached for the reaction $\mathrm{Fe}(\mathrm{III}) \stackrel{+e}{\longrightarrow} \mathrm{Fe}(\mathrm{II})$, hence, the subsequent increase of $\mathrm{j}_{\mathrm{K}}{ }^{\text {overall }}$ under the other equal conditions, will not provoke the increase in this reaction rate.

It was interesting to compare the given dependencies with the polarization distribution for the reaction $\mathrm{Fe}(\mathrm{II}) \stackrel{+2 e}{\longrightarrow} \mathrm{Fe}^{0}$. It follows from the data of Figure 3B that, as well as for the previous case, the polarization distribution curve is characterized with maximum, which is however located closer to the back side of the electrode. The maximal polarization values are thus reached on the front side of it.

At the same time the distribution of the local current densities along the electrode depth was considered (Figure 4). For the reaction $\mathrm{Fe}(\mathrm{III}) \stackrel{+e}{\longrightarrow} \mathrm{Fe}$ (II) these values on the back side of electrode surface were essentially higher than on the front one; this difference increases with the increase of the overall current density to $1000-1500 \mathrm{~A} / \mathrm{m}^{2}$, remaining unchanged with its further increasing. 
For the reaction $\mathrm{Fe}(\mathrm{II}) \stackrel{+2 e}{\longrightarrow} \mathrm{Fe}^{0}$ the highest values of the local current densities were characteristic for the front side of the electrode. Within the range $\mathrm{j}_{\mathrm{K}}$ overall $=1500-2000 \mathrm{~A} / \mathrm{m}^{2}$ this difference between the values of the current on the front and back side of the electrode is insignificant, but essentially increases with the increase of $\mathrm{j}_{\mathrm{K}}{ }^{\text {overall }}$ up to 3000 $\mathrm{A} / \mathrm{m}^{2}$ and higher which corresponds to the conditions of the deposition of metal iron.
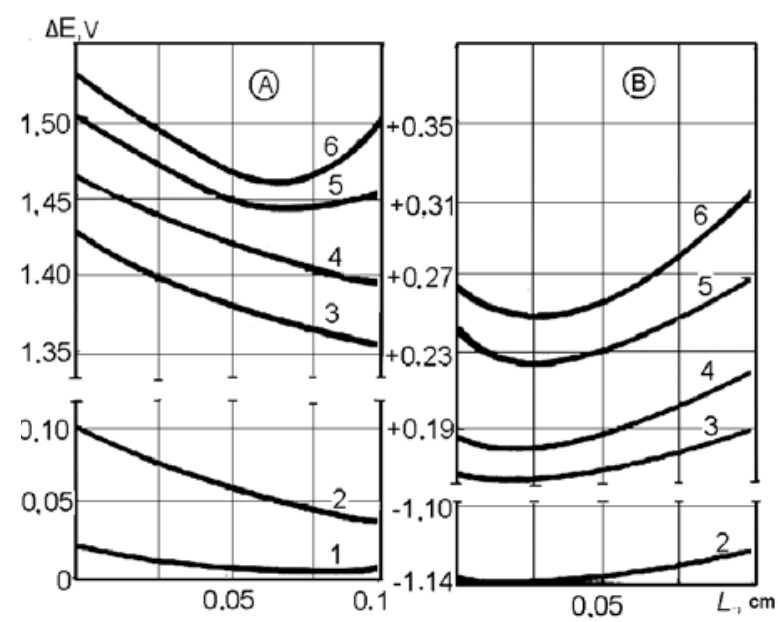

Figure 3. Profiles of polarization distribution for the reactions $\mathrm{Fe}(\mathrm{III}) \stackrel{+e}{\longrightarrow} \mathrm{Fe}$ (II) (A) and $\mathrm{Fe}(\mathrm{II}) \stackrel{+2 e}{\longrightarrow} \mathbf{F e}^{\mathbf{0}}(\mathrm{B})$ along the depth of TDE in dependence on current density, $\mathrm{A} / \mathrm{m}^{2}$ :

1-300; 2-500; 3-700; 4-1000; 5-3000; 6-5000. The conditions are the same as related to Figure1.
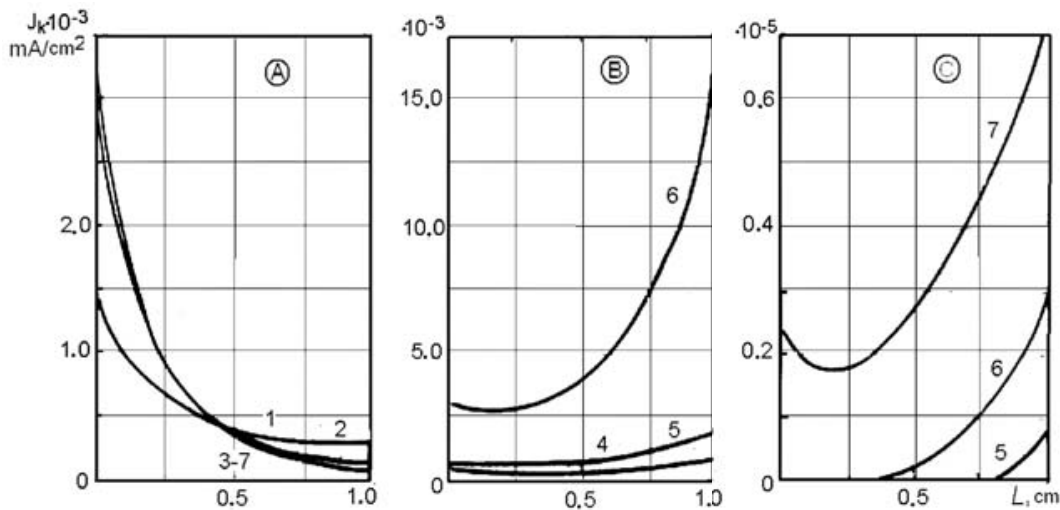

Figure 4. Profiles of the local current densities distribution of the reactions $\mathrm{Fe}(\mathrm{III}) \stackrel{+e}{\longrightarrow} \mathrm{Fe}(\mathrm{II})$ (A),

$\mathrm{Fe}(\mathrm{II}) \stackrel{+2 e}{\longrightarrow} \mathrm{Fe}^{0}(\mathrm{~B})$ and $2 \mathrm{H}^{+}+\mathbf{2 e} \rightarrow \mathrm{H}_{2}$ (C) along the TDE depth in dependence on the current densities, $\mathrm{A} / \mathbf{m}^{2}: 1-500 ; 2-700 ; 3-1000 ; 4-1500 ; 5-2000 ; 6-3000 ; 7-5000$.

Conditions: electrode material VINN-250 (2-times compressed); $S_{\mathrm{v}}=560 \mathrm{~cm}^{2} / \mathrm{g} ; \in=0.925$;

$$
\chi_{S}=0.4 \Omega / \mathrm{cm} ; \mathbf{u}=0.1 \mathrm{~mL} / \mathrm{s} \text {. }
$$

As it was shown by calculations (Figure 4B), under $\mathrm{j}_{\mathrm{K}}$ overall $\approx 2000 \mathrm{~A} / \mathrm{m}^{2}$ and higher under the selected conditions, the hydrogen emission begins, which causes the current consumption for this process. As for the case of the $\mathrm{Fe}^{\mathrm{o}}$ deposition, the current density value is higher on the front side than on the back one, which indicates on the more intensive hydrogen emission on this side of the electrode.

\section{Effect of the electrode thickness and degree of its compression}

An important factor influencing the process efficiency on the CFE, is the high reaction surface. The increase of the total surface of these electrodes can be reached by two ways: increase of either their overall size or of their depth.

The second way is rational, as it makes it possible to develop the small-size equipment. However, the increase of the CFE depth has limitations connected with a number of factors, first of all, with the non-uniform distribution of the electrochemical process intensity within the electrode depth, which can be explained by the Ohmic losses. The maximal value of the electrochemical processes efficiency is determined by the electrode surface working under the conditions of the limiting diffusion current with regard to the ions of the main electroactive component [15].

Experimental study of the distribution of polarization, as well as substance concentration and local current densities along the CFE depth is difficult from the methodical point of view. However, there are publications in this field in which the experimental results are in agreement with the theoretical data obtained by calculations [16]. It can be concluded that the mathematical model can describe the real processes with certain reliability. 
The dependence $\mathrm{C}_{0} / \mathrm{C}_{\tau}$ from $L$ obtained by calculations (Figure 5) testifies that the efficiency of Fe(III) ions reduction to $\mathrm{Fe}(\mathrm{II})$ increases with the electrode depth. Once the electrode depth values reach the value of $L=0.1-0.3 \mathrm{~cm}$, $\mathrm{C}_{0} / \mathrm{C}_{\tau}$ remains constant. This regularity can be explained, knowing the distribution of the reacting ions concentration, current density and polarization within the porous electrode.

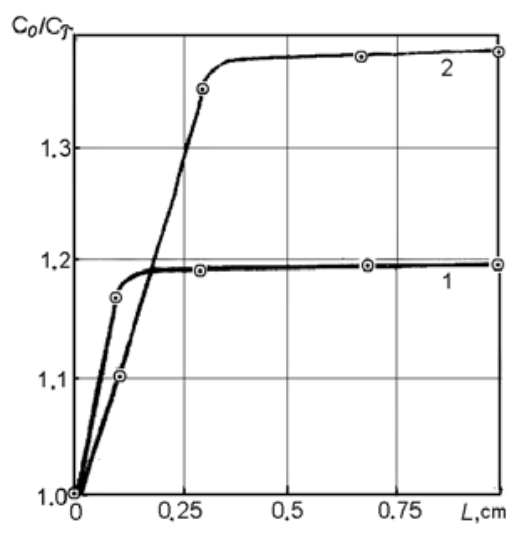

Figure 5. Effect of the TDE depth on the change in $\mathrm{C}_{\mathrm{o}} / \mathrm{C}_{\tau}$ values in dependence on the overall current density, $\mathrm{A} / \mathrm{m}^{2}: \mathbf{1}-\mathbf{5 0 0} ; 2-1000$.

Conditions: electrode material VINN-250;

$$
\mathbf{u}=0.36 \mathrm{~mL} / \mathrm{s} ; \mathrm{C}_{\text {initial }}^{E(I I I)}=\mathbf{8 . 9} \cdot 10^{-3} \mathrm{~mol} / \mathrm{L} \text {. }
$$

At the low electrode thickness of $0.05 \mathrm{~cm}$ (Figure 6, curve 1), the polarization values on the back and front sides are almost the same, inside the electrode being the minimum of polarization. With the increase of L, the non-uniformity of $\Delta \mathrm{E}$ distribution is increased, but in all the cases the polarization on the front side is higher than on the back one. At the same time, $\Delta \mathrm{E}$ values at the internal part of electrode are reduced, approaching to zero. The higher $\mathrm{L}$ value, the higher part of the internal surface of electrode has the minimal $\Delta \mathrm{E}$ values, or absence of polarization. The latter fact testifies that there is no reaction of $\mathrm{Fe}(\mathrm{III})$ reaction running on this part of the electrode.

Further increase of the electrode thickness to $2 \mathrm{~cm}$ provokes the polarization shift inside the electropositive side, with the appearance of anodic zone (Figure 6, curve 5). Occurrence of the similar anodic zones is described in [17], where their formation is explained with the uniformity worsening of polarization distribution inside the electrode due to the Ohmic losses. In this case in the internal part of electrode the reverse process of $\mathrm{Fe}(\mathrm{II})$ ions oxidation to Fe(III) can be running. The calculation results obtained make it possible to suppose that the increase of the electrode thickness above some optimal value will result in the undesired processes, worsening the operation of CFE during the regeneration of iron plating electrolytes.

The curves of polarization distribution for the reaction $\mathrm{Fe}(\mathrm{II}) \stackrel{+2 e}{\longrightarrow} \mathrm{Fe}^{\circ}$ (Figure $6 \mathrm{~B}$ ) have the character similar to the appropriate curves for the reaction $\mathrm{Fe}(\mathrm{III}) \stackrel{+e}{\longrightarrow} \mathrm{Fe}(\mathrm{II})$. In follows from these data that under the low thicknesses of electrodes the probability of $\mathrm{Fe}(\mathrm{II})$ ions reduction to metal is increasing, especially on the front side of the electrode, where the polarization is higher.

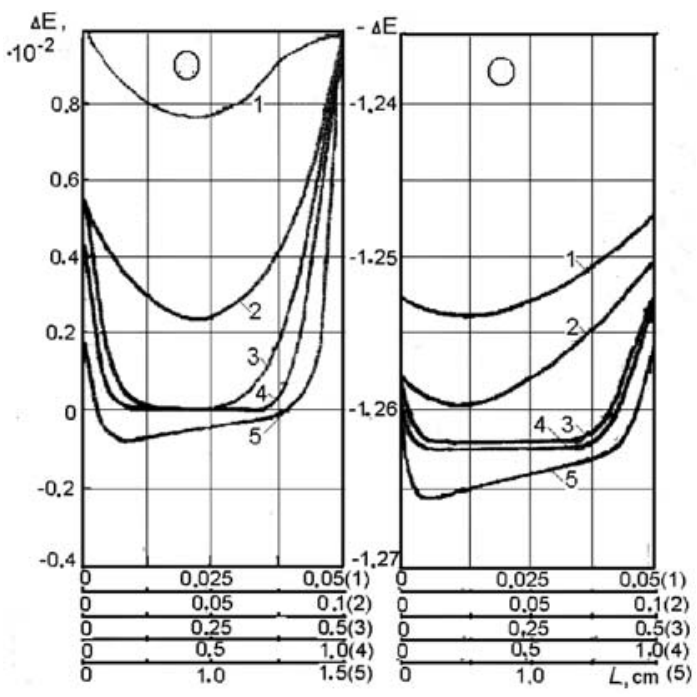

Figure 6. Profiles of polarization distribution of the reactions $\mathrm{Fe}(\mathrm{III}) \stackrel{+e}{\longrightarrow} \mathrm{Fe}(\mathrm{II})$ (A) and $\mathrm{Fe}(\mathrm{II}) \stackrel{+2 e}{\longrightarrow} \mathrm{Fe}^{\mathbf{0}}(\mathrm{B})$ with the change of threedimensional electrode depth (TDE), cm: 1-0.05; $2-0.1 ; 3-0.5 ; 4-1.0 ; 5-2.0$.

With the increase of $\mathrm{L}$ values, the polarization distribution for the reaction considered $\mathrm{Fe}(\mathrm{III}) \stackrel{+e}{\longrightarrow} \mathrm{Fe}(\mathrm{II})$ becomes more non-uniform. The profiles of local current density distribution (Figure 7A) are also characterized with the essential decrease of these values in the depth of electrode with the increase of its thickness.

So, with the polarization and current density decrease inside the electrode, the part of its internal surface, on which the target reaction runs with the high sufficient rate, is decreasing with the increase of the electrode thickness. 
This is confirmed with the data on Fe(III) ions concentration distribution inside the electrode (Figure 7B). It follows from the calculated dependencies that for the conditions selected by us, the maximal value of electrode thickness should not exceed $0.15-0.30 \mathrm{~cm}$. However, in view of the fact that the kinetic and other parameters chosen for the calculations, can differ from the real values, it can be considered that for the practical scopes the electrode thickness can be increased to $0.6-0.9 \mathrm{~cm}$, when its internal surface works intensively enough, or at least is not connected with the decrease in the process rate of $\mathrm{Fe}(\mathrm{III})$ ions reducing.
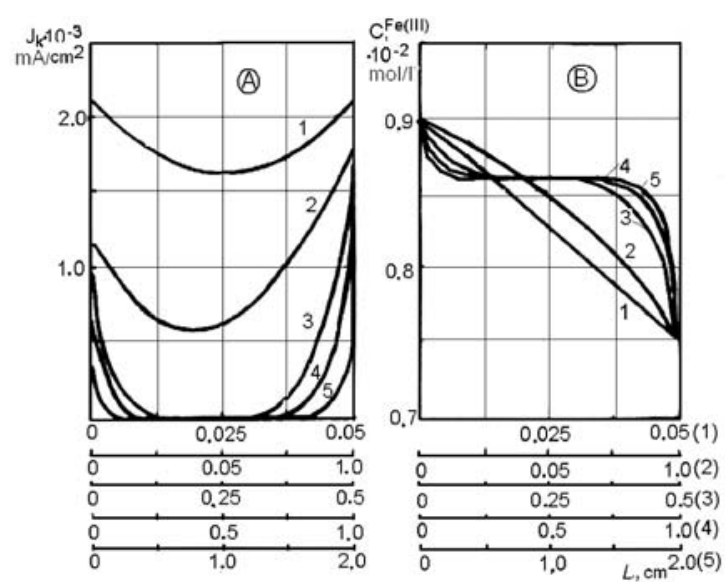

Figure 7. Profiles of the local current densities

distribution of the reactions $\mathrm{Fe}(\mathrm{III}) \stackrel{+e}{\longrightarrow} \mathrm{Fe}$ (II)

(A) and change in $\mathrm{Fe}(\mathrm{III})$ ions concentration (B) with

the change in TDE depth, cm:

$1-0.05 ; 2-0.1 ; 3-0.5 ; 4-1.0 ; 5-2.0$.

It was of specific interest to assess, with the help of the calculations by the mathematical model, the influence of CFE compression degree on studied process. It was found that the maximum process efficiency is reached when the CFE were 2.0-2.2 times compressed, and above this value the efficiency was decreased. At the 5-times compression, in spite of the appropriate increase in the reaction surface from 280 to $1400 \mathrm{~cm}^{2} / \mathrm{g}$ of the material VINN-250 and increase of its electroconductivity from 0.1 to $0.9 \Omega / \mathrm{cm}$, the rate of the process $\mathrm{Fe}(\mathrm{III}) \stackrel{+e}{\longrightarrow} \mathrm{Fe}(\mathrm{II})$ turned out to be even low, than for this material in the initial state. In this case the porosity of the material was decreased from 0.97 to 0.83 .

With the increase of compression up to 2.0-2.2 times, the part of the internal surface, working efficiently enough, was decreased, and polarization in the depth of the electrode was reduced. The current density distribution is similar to the appropriate polarization changes. However, the values of polarization and current density on the back side are thus increased, which causes the acceleration of the target process under these conditions.

With the 3-times and more increase in the compression degree, the polarization distribution inside the electrode becomes more non-uniform, at the same time its values on the CFE sides are decreased. Correspondingly, the total electrode surface on which the target process runs with the sufficient rate is reduced.

In this way, the data obtained by calculation method, have shown that the optimal is 2-times compression of $\mathrm{CFE}$, which ensures the highest rates of $\mathrm{Fe}(\mathrm{III})$ ions reduction to $\mathrm{Fe}(\mathrm{II})$.

\section{Effect of the cathode material}

It is known from the literature [5,6], that the commercially produced carbonic-fibrous materials possess various properties, which may render the essential effects on the rates of electrochemical processes, including those running during the regeneration of iron-containing electrolytes. To compare the operation of electrodes made of various types of CFM, it is necessary to study the distribution of polarization, current and concentration within their body.

The results of the numerical calculations of concentration changes within the electrode body (Figure 8A) under the selected electrolysis conditions testify that the most uniformly the studied process runs when the TVS brand of CFM was used. For the other materials the highest process intensity was detected in the proximity of the external sides of electrode. For such materials as VNG-50, VINN-250, NTM-200 the back side was working worse than the front one, whereas for the materials KNM and BBP-66-95 - on the contrary. The materials brands TGN and NTM-100 have demonstrated the intermediate position in this line, and the curves of concentration distribution are symmetric. The central part of the electrodes, like for the other studied materials (except of TVS), is practically not working.

The comparison of polarization distribution curves on studied materials (Figure 8B) has also demonstrated the essential difference of CFM of TVS brand from the other materials. For the other materials the polarization was changed on the depth of $0.1 \div 0.12 \mathrm{~cm}$ on each of the sides, and its value makes on the electrode surface from $4 \cdot 10^{-3}$ to $15-20 \cdot 10^{-3} \mathrm{~V}$. In case of TVS brand, under these conditions, the polarization was changes from $7.6 \cdot 10^{-2}$ to $11.1 \cdot 10^{-2} \mathrm{~V}$ on the lateral surfaces and does not decrease below $6.6 \cdot 10^{-2} \mathrm{~V}$ in the electrode depth. The front side is thus polarized more then the back one. The distribution of local current densities, like in the previous cases, has the character similar to the polarization distribution. 
The calculated data obtained give rise to assumption that the rate of the studied process will be the highest for TVS brand of CFM. For the other studied materials is would be possible to slightly reduce the electrode thickness, without causing the essential effect on process rate, as soon as the internal zones with the insignificant polarization were observed for them. This, in its turn, will make it possible to reduce the hydraulic resistance during the electrolyte pumping.

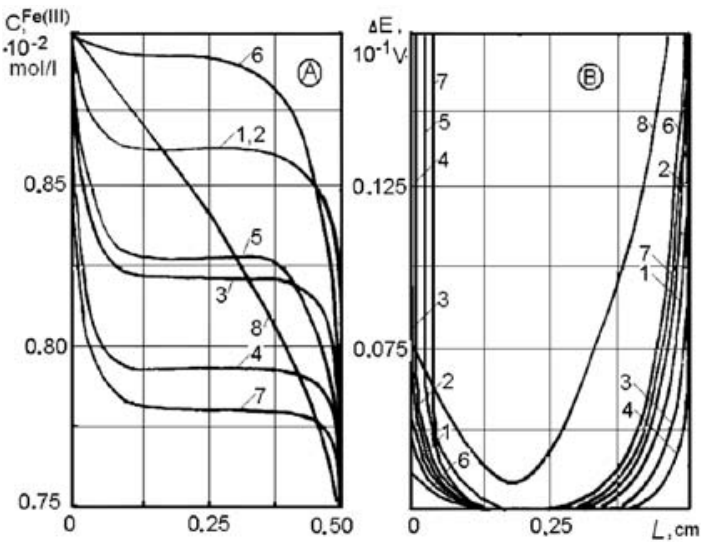

Figure 8. Profiles of Fe(III) ions concentrations (A) and polarization (B) along the TDE depth in dependence on the electrode material type: 1-VINN-250; 2-NTM-200; 3-NTM-100; 4-VVP-66-95; 5-TNG; 6-VNG-50; 7-KNM; 8-TVS.

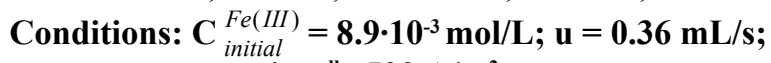

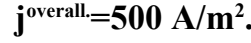

\section{Effect of the initial concentration of Fe(III) ions}

The studies of metals electrochemical reducing from low-concentrated solutions has shown [18], that process efficiency decreases with the increase of the electroactive component concentration. At the same time, there is a range of concentrations specific for each process, in which the rate of metal reducing is the highest. Like in the previous cases, this can be confirmed with the data of polarization and metal ions concentration, as well as current density distribution within the electrode body. It is important to determine these dependencies on the base of the numerical calculations using the mathematical model, as it allows determining the optimal conditions of iron plating solutions regeneration. With the increase of $\mathrm{Fe}(\mathrm{III})$ ions concentration up to $8.9 \cdot 10^{-3} \div 1.8 \cdot 10^{-2} \mathrm{~mol} / \mathrm{L}$, the rate of the studied process is decreasing (Figure 9). However, with the increase of the overall current density to $1500 \div 3000 \mathrm{~A} / \mathrm{m}^{2}$ even under the high concentrations of $\mathrm{Fe}(\mathrm{III})$ ions, the high enough reaction rate is reached.

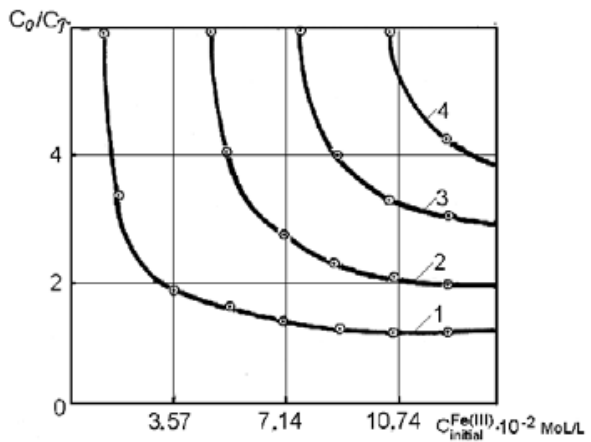

Figure 9. Change of $\mathrm{Fe}(\mathrm{III})$ ions concentration (during the one-time pass through the CFE) in dependence on their initial contents in the electrolyte under the current densities, $\mathrm{A} / \mathbf{m}^{2}$ : $1-500 ; 2-700 ; 3-1000 ; 4-2000$.

Conditions: electrode material VINN-250 (2-times compression); $\mathrm{u}=0.1 \mathrm{~mL} / \mathrm{s} ; L=0.5 \mathrm{~cm}$.

Distribution of the cathode polarization within the electrode body (Figure 10) also demonstrates the essential influence of metal initial concentration: it's the lower $\mathrm{C}^{\mathrm{Fe}(\mathrm{III})}{ }_{\text {initial }}$ in the solution, the higher is the level of cathode polarization within the CFE depth, and the higher is the efficiency of these electrodes work. Under the high enough concentration of $\mathrm{Fe}$ (III) ions in electrolyte, in the central part of the electrode the minimum polarization is observed, where $\mathrm{Fe}(\mathrm{III})$ reduction to $\mathrm{Fe}(\mathrm{II})$ practically do not occur. This area is broadening with the increase in $\mathrm{C}_{\text {initial }}$.

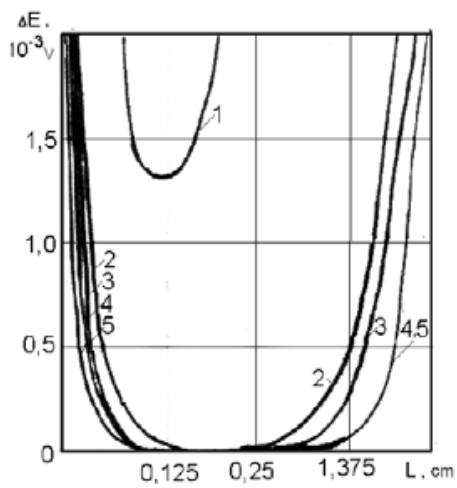

Figure 10. Polarization distribution for the reaction $\mathrm{Fe}(\mathrm{III}) \stackrel{+e}{\longrightarrow} \mathrm{Fe}(\mathrm{II})$ under the initial contents in $\mathrm{Fe}(\mathrm{III})$ ions, mol/L: $1-1.8 \cdot 10^{-3} ; 2-8.9 \cdot 10^{-3} ; 3-1.8 \cdot 10^{-2}$; $4-8.9 \cdot 10^{-2} ; 5-1.8 \cdot 10^{-1}$. 
The study of Fe(III) ions distribution within the electrode has shown that the reduction processes occur only in the near-surface electrode layers, more intensively at the front side. With the decrease of Fe(III) ions concentration, the internal area of electrode, where the reduction of $\mathrm{Fe}(\mathrm{III})$ to $\mathrm{Fe}(\mathrm{II})$ occurs, is making broader, and under $\mathrm{C}^{\mathrm{Fe}(\mathrm{III})}=1.8 \cdot 10^{-3} \div 5.36 \cdot 10^{-3} \mathrm{~mol} / \mathrm{L}$ and $j=500-1500 \mathrm{~A} / \mathrm{m}^{2}$ the entire depth of the electrode is working at $\mathrm{L}=0.5 \mathrm{~cm}$.

As follows from the data obtained, at the concentrations of $\mathrm{Fe}(\mathrm{III})$ ions of $8.9 \cdot 10^{-2} \mathrm{~mol} / \mathrm{L}$ and higher, the thickness of CFE needs to be diminished up to $0.2-0.3 \mathrm{~cm}$, thus decreasing the electrode area where Fe(III) are reduced. At the same time, electrolyte regeneration occurs with the permanent decrease of $\mathrm{C}^{\mathrm{Fe}(\mathrm{III})}$, and with time the internal part of electrode is broadening in which the studied reaction runs. In its turn, this requires to increase the total electrode up to $0.5 \mathrm{~cm}$ and higher.

\section{Influence of the solution flow rate}

The rate of the electrolyte flow through the three-dimensional electrode is one of the technological parameters, which can be varied in order to modify the rate of the targeted process. With the increase of $u$ values, the rate of Fe(III) reduction to $\mathrm{Fe}(\mathrm{II})$ is decelerating (Figure 11), which is caused by the one-time pass of the solution through the electrode body.

However, the results of polarization studies allow supposing that under the conditions of repeated pumping of treated solution through the electrode, the rate of target reaction should be increased, as it is controlled by the diffusion. Therefore, the acceleration of flow rate, like the agitation, results in the increase in the limiting diffusion current, thus accelerating the electrode process. The opposite influence of this factor detected at the calculations in accordance with the mathematical model, may be connected with the fact that not all the solution flowing during one-time pass through the CFE, interacts with the electrode surface.

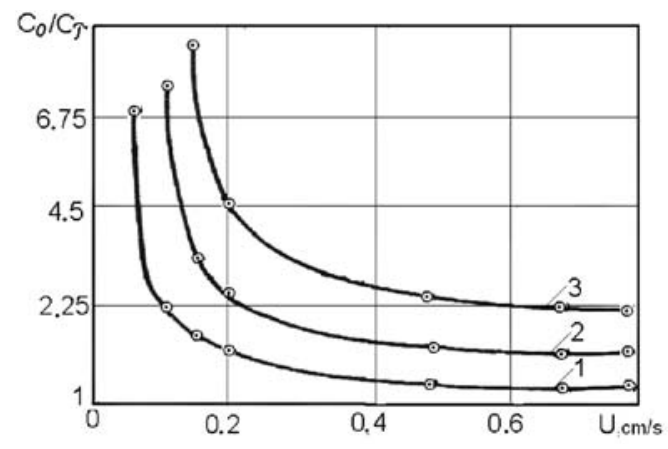

Figure 11. Effect of the solution flow velocity on the reduction of $\mathrm{Fe}$ (III) ions to $\mathrm{Fe}$ (II) with the change in current density, $\mathrm{A} / \mathrm{m}^{2}$ : $1-500 ; 2-1000 ; 3-1500$.

With the increase of the overall current density up to $1000 \div 1500 \mathrm{~A} / \mathrm{m}^{2}$ the reduction efficiency of Fe(III) ions is increasing, although the character of dependencies remains the same. At certain part of CFE the limiting current for the target reaction is reached.

It was of special interest to consider the work of the internal area of the electrode (Figure 12). At the flow rate $0.05 \div 0.10 \mathrm{~cm} / \mathrm{s}$, the profile of concentration distribution has a tendency to the continuous decrease from the back to the front side of the electrode, but on a certain portion inside the electrode the rate of Fe(III) ions reducing becomes slower. At the flow rate of $0.15 \mathrm{~cm} / \mathrm{s}$ and higher, the horizontal portions are discernible on the curves, which size increases with the increase in $u$ values. This dependence is correlating with the polarization distribution data along the electrode depth. Thus, at the flow rate of $0.07 \mathrm{~cm} / \mathrm{s}$ through the $0.5 \mathrm{~cm}$ electrode, the value of polarization for the reaction $\mathrm{Fe}(\mathrm{III}) \stackrel{+e}{\longrightarrow} \mathrm{Fe}(\mathrm{II})$ is decreased to minimal, equal to $0.2 \cdot 10^{-3} \mathrm{~V}$, and the minimum is on the $1 / 4$ distance of electrode thickness from its back side. With the increase in $u$ values from $0.15 \mathrm{~cm} / \mathrm{s}$ and higher, the shift of the polarization minimum is observed to the center of electrode, with the simultaneous decrease of its values close to zero. The similar changes undergo also the profiles of current density distribution, consumed for the reaction $\mathrm{Fe}(\mathrm{III}) \stackrel{+e}{\longrightarrow} \mathrm{Fe}$ (II).

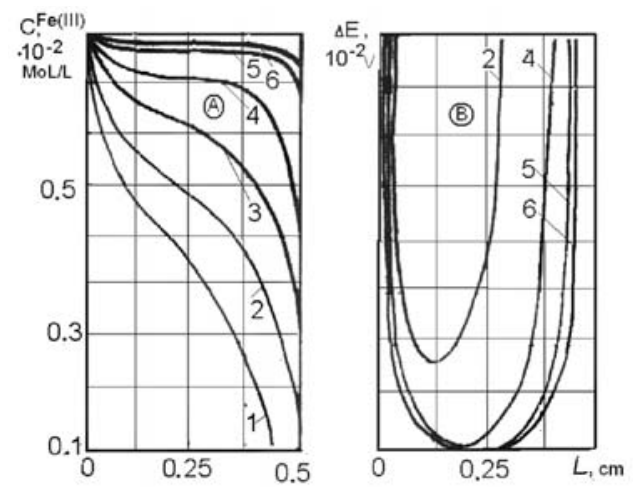

Figure 12. Profiles of Fe(III) ions concentration (A) and polarization (B) within the TDE depth in dependence on the flow velocity, $\mathrm{cm} / \mathrm{s}$ : $1-0.05 ; 2-0.07 ; 3-0.1 ; 4-0.15 ; 5-0.5 ; 6-1.0$. 
In this way, the calculation data show that by decreasing the flow rate to certain values it is possible to increase the internal area of electrode where the target process occurs with the sufficient intensity. From the practical viewpoint, the reducing of flow rate makes it possible to reduce the energy consumption for the electrolyte pumping, as well as to reduce its turbulization, so as to prevent the reduction of $\mathrm{Fe}$ (II) ions to $\mathrm{Fe}$ (III) in the regenerated iron-containing electrolyte by air oxygen.

The data given in Figure 13 demonstrate the joint reduction of oxygen and Fe(III). The polarization distribution curve, corresponding to the reaction $\mathrm{Fe}(\mathrm{III}) \stackrel{+e}{\longrightarrow} \mathrm{Fe}(\mathrm{II})$ (Figure 13B, curves 1,2), at the electrode thickness of $0.1 \mathrm{~cm}$ has a maximum, which at the increase of $\mathrm{L}$ values to $0.5 \mathrm{~cm}$ is shifted from the front to the back side of the electrode, which is similar to the current density change under these conditions (Figure 13D). With the increase in L values on the part of the electrode, corresponding to the decrease in polarization and local current density, the $C^{\mathrm{Fe}(\mathrm{III})}$ values are not changed, but then they sharply decrease with the increase of $\Delta E$ and $j$ values towards the back side of the CFE.
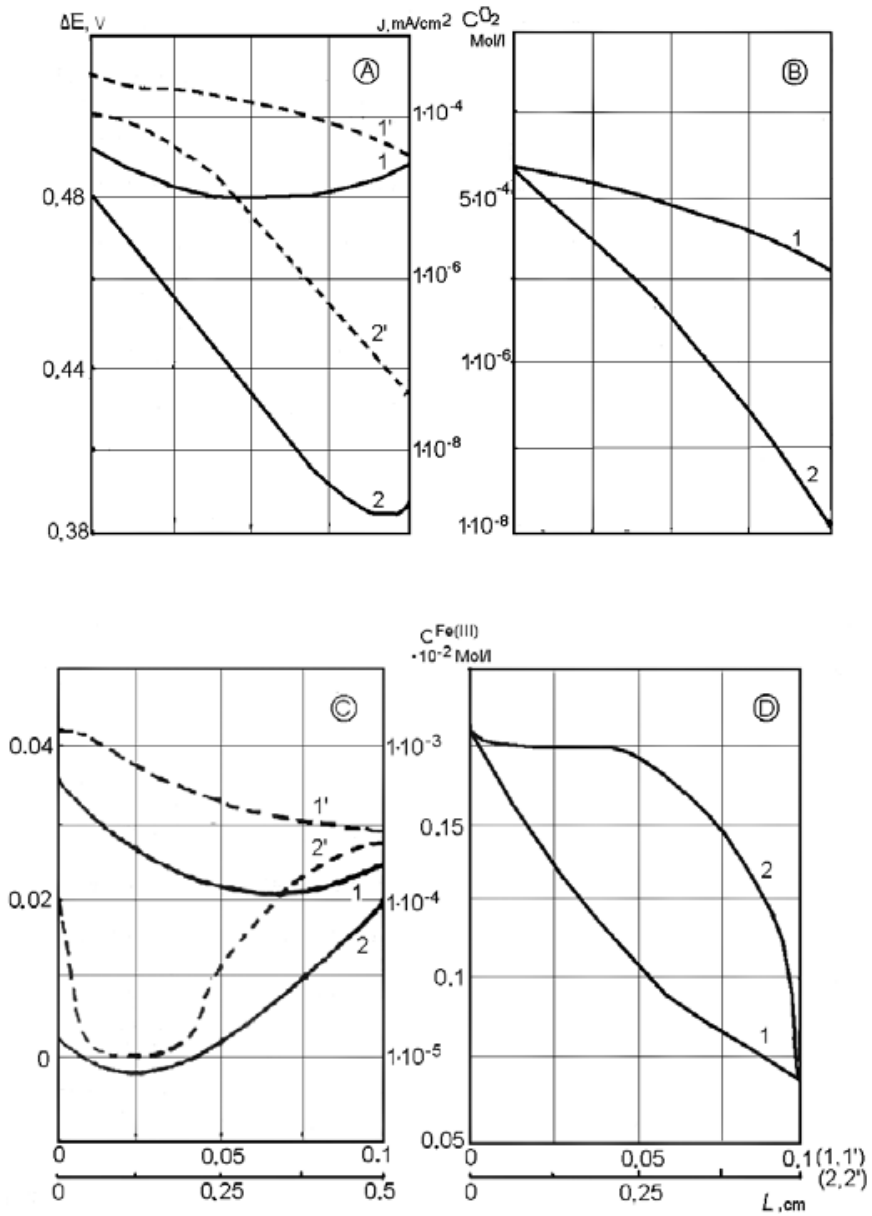

Figure 13. Change in the polarization distribution (dotted line) - (A, B) and concentration $(C, D)$ during the reaction of oxygen reducing $(\mathrm{A}, \mathrm{B})$ and $\mathrm{Fe}(\mathrm{III})$ within the CFE depth, cm: 1,1'- $0.1 ; 2,2$ ' -0.5 . Conditions: electrode material VINN-250 (2-fold compression); $u=0.36 \mathrm{~mL} / \mathrm{s}$;

$$
\begin{gathered}
\mathbf{j}_{\mathbf{k}}=\mathbf{5 0 0 \mathrm { A } / \mathbf { m } ^ { 2 }} ; \\
\mathbf{E}_{P}^{O_{2}}=\mathbf{1 . 1 V} ; \mathbf{j}_{o}^{O_{2}}=\mathbf{1 0} \mathbf{1 0}^{-8} \mathrm{~A} / \mathbf{c m}^{2} ; \mathbf{z}^{O_{2}}=\mathbf{2} \\
\mathbf{C}_{o}^{O_{2}}=\mathbf{2} \cdot \mathbf{1 0 ^ { - 4 }} \mathbf{~ m o l} / \mathbf{L}
\end{gathered}
$$

The values of polarization and current, consumed for the oxygen reduction reaction (Figure 13A), are reduced from the back side of CFE to the front one, the polarization distribution having the minimum shifting towards the front side with the increase in $L$ value. With the increase of the electrode thickness, the more intensive oxygen reduction is observed (Figure 14B).

Another side the process with regard to the target reaction of $\mathrm{Fe}(\mathrm{III})$ ions reduction to $\mathrm{Fe}(\mathrm{II})$ in the iron-plating electrolyte is hydrogen emission. The calculation made for the three-component system, including the reduction of hydrogen ions, shows that the polarization distribution at the reaction occurrence $\mathrm{Fe}(\mathrm{III}) \stackrel{+e}{\longrightarrow} \mathrm{Fe}$ (II) is characterized with the decrease of its values from the back to the front side of the electrode (Figure 14). At the low current densities, the polarization changes uniformly the electrode depth, and with the increase of $j_{\text {overall }}$ values, the minimum appears in the internal area of the electrode.

The curves of polarization distribution for the reaction $\mathrm{Fe}(\mathrm{II}) \stackrel{+2 e}{\longrightarrow} \mathrm{Fe}^{\mathrm{o}}$ (Figure 15B) show that the polarization is higher on the front side of the electrode than on the back one. At the same time, the numerical polarization values for this reaction is lower than for the reaction $\mathrm{Fe}(\mathrm{III}) \stackrel{+e}{\longrightarrow} \mathrm{Fe}(\mathrm{II})$, which indicates its easier occurrence in the negative potentials area, in which these two processes run simultaneously. 

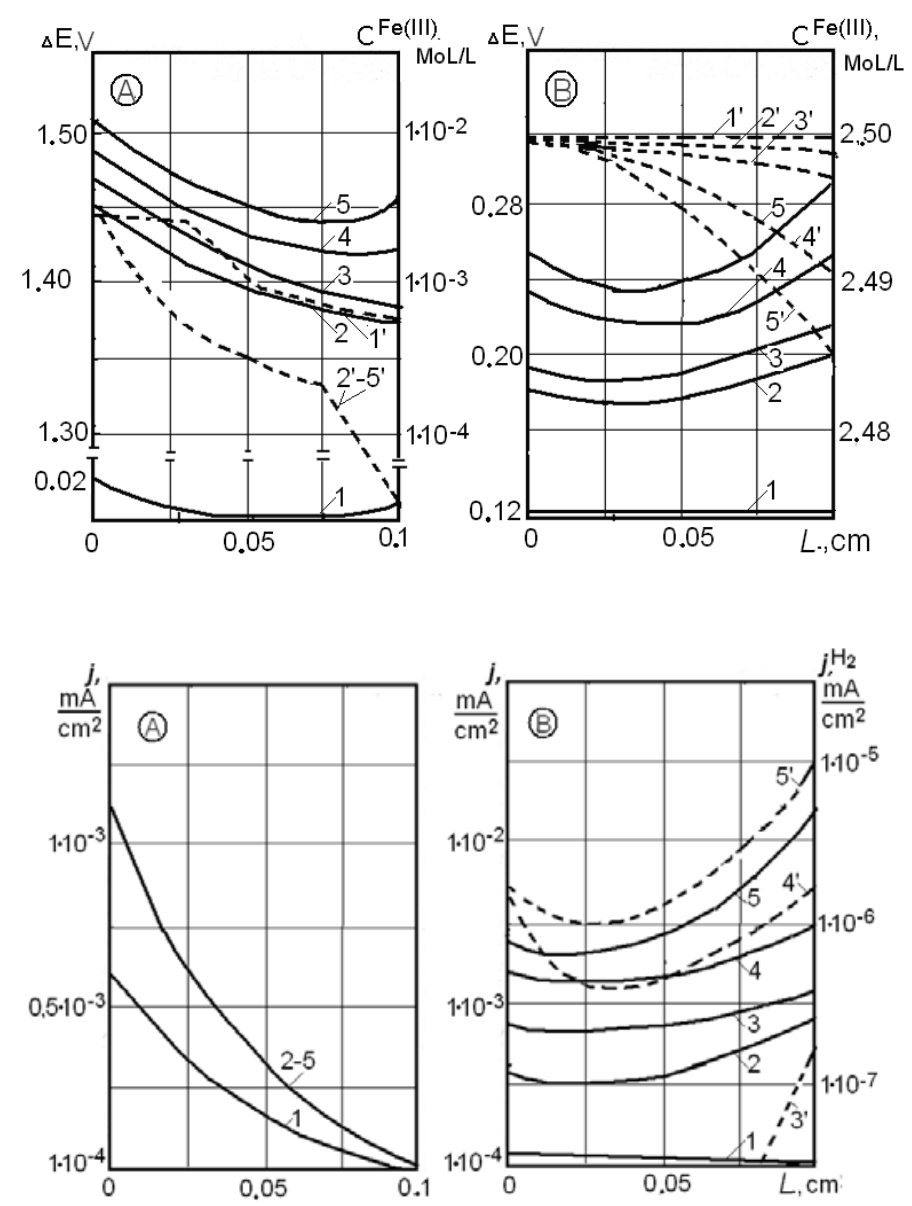

Figure 14. Distribution of polarization (curves $1-5)$ and concentration (curves 1'-5') for the reaction $\mathrm{Fe}(\mathrm{III}) \rightarrow \mathrm{Fe}(\mathrm{II})$ (A) and $\mathrm{Fe}(\mathrm{II}) \rightarrow \mathrm{Fe}^{0}$ (B) with change in current density, $\mathbf{A} / \mathbf{m}^{2}$ :

$1,1^{\prime}-100 ; 2,2^{\prime}-500 ; 3,3^{\prime}-700 ; 4,4^{\prime}-1500$;

5,5 ' 3000. The conditions are similar to those shown on Figure 13.
Figure 15. Distribution of current for the reaction $\mathrm{Fe}(\mathrm{III}) \stackrel{+e}{\longrightarrow} \mathrm{Fe}(\mathrm{II})$ (A) and

$\mathrm{Fe}(\mathrm{II}) \stackrel{+2 e}{\longrightarrow} \mathbf{F e}^{\mathbf{0}}$ and hydrogen emission (dotted line) (B) in dependence on current density, $A / \mathbf{m}^{2}: 1$ - 100; 2 - 500; 3,3' - 700; 4,4 ' $-1500 ; 5.5$ ' -3000 . The conditions are similar to those shown on Figure 13.

Under these conditions, the concentration of Fe(III) is distributed uniformly within the CFE body. With the current density increase, when the side processes start to occur, the $\mathrm{C}^{\mathrm{Fe}(\mathrm{III})}$ distribution within the electrode body is practically not changed. The data of Figure 14B demonstrate that the change of the Fe(II) ions in the electrolyte proceeds uniformly, with the increase in the overall current density, from back to the front side of the electrode.

At the low electrode thickness $(0.1 \mathrm{~cm})$, used in our calculations, the curves of the current density distribution, consumed for the reaction $\mathrm{Fe}(\mathrm{III}) \stackrel{+e}{\longrightarrow} \mathrm{Fe}(\mathrm{II})$, have a tendency to decrease from the back to the front side of the CFE, although starting with $j_{\text {overall }}=500 \mathrm{~A} / \mathrm{m}^{2}$ and higher, the current density distribution remains unchanged (Figure 15).

It was also found that under the current densities below $500 \mathrm{~A} / \mathrm{m}^{2}$ under the considered conditions, according to calculations, the hydrogen emission is not running, that can be explained by high overvoltage of its emission on the graphite surface [7]. At $j_{\text {overall }}=700 \mathrm{~A} / \mathrm{m}^{2}$ hydrogen starts evolving mainly on the back side of the electrode, and with the further increase in current density it is reduced within the entire electrode body, on the front side more than on the back one. The curves of current density distribution for hydrogen release reaction have minimum which is placed closer to the back side of the CFE. In this way, running of all the considered reactions has an independent character, the reduction of $\mathrm{Fe}(\mathrm{III})$ ions to $\mathrm{Fe}$ (II) running more intensively on the back side of the CFE, whereas two other processes connected with the evolving of metal iron and hydrogen on the front side of the electrode.

\section{Conclusions}

The calculation results using the mathematical model, regarding the reduction processes in the iron plating electrolytes on the three-dimensional electrodes made it possible to study the effect of the overall current density, CFE thickness and degree of its compression, solution flow rate through the electrode, initial concentration of Fe(III) ions in the solution and CFM type on the efficiency of Fe(III) reduction.

The results obtained make it possible to select more purposely the conditions of iron electrolytes regeneration. Selecting the appropriate regimes, it would be possible to ensure the best conditions for the reduction of Fe(III) ions to $\mathrm{Fe}(\mathrm{II})$ in these electrolytes. The trends revealed require the experimental tests related to the real practical regeneration of such electrolytes. 


\section{References}

1. Varentsov, V.K.; Koshev, A.N. Mathematical modeling of the electrochemical processes in the flow-through threedimensional electrodes. Proceedings of Siberian Branch of Academy of Sciences of USSR, Chemical Series, 1988, 17, pp. 117-125 (in Russian).

2. Koshev, A.N.; Kuzina, V.V. Elaboration and study of mathematical models on non-stationery processes in electrochemical reactors with flow-through three-dimensional electrodes. PSUAC: Penza, 2011, 119 p. (in Russian).

3. Koshev, A.N.; Varentsov V.K.; Kamburg, V.G. Mathematical modeling of metals electrodeposition from the multicomponent systems on flow-through three-dimensional electrodes. Proceedings of Siberian Branch of Academy of Sciences of USSR, Chemical Series, 1984, 6(5), pp. 24-27 (in Russian).

4. Daniel-Beck, V.S. On the polarization of porous electrodes. 4. Effect of the solid phase resistance on the potential and current distribution in the electrode. Electrochemistry, 1966, 2(6), pp. 672-677 (in Russian).

5. Varentsov, V.K.; Jerebilov, A.F.; Malei, M.D. Carbonic graphite fibrous materials - new electrodes for metals extraction from the diluted solutions. 1. Nonwoven carbonic graphite fibrous materials. Proceedings of Siberian Branch of Academy of Sciences of USSR, Chemical Series, 1984, 6(17), pp. 120-127 (in Russian).

6. Beck, R.Yu.; Zamyatin, A.P. Mass-transfer coefficient and surface of the flow-through fibrous electrodes, available for electrolysis. Electrochemistry, 1978, 14(18), pp. 1196-1201 (in Russian).

7. Covaliova, O.V. Electrochemical study of the redox processes in the iron-containing water solutions. Studia Universitatis, Natural Sciences Series, 2009, 21(1), pp. 195-203 (in Russian).

8. Covaliova, O.V. The study of kinetic regularities of Fe(III) ions reduction to Fe(II) in concentrated electrolytes. Studia Universitatis, Natural Sciences Series, 2013, 26(6), pp. 195-203 (in Russian).

9. Sukhotin, A.M. Ed. Reference Book on Electrochemistry. Chemistry: Leningrad, 1981, 488 p. (in Russian).

10. Fetter, K. Electrochemical kinetics. Chemistry: Moscow. 1967, 856 p. (in Russian).

11. Melkov, M.P.; Namakonov, B.V. On the cathode process of iron electrodeposition. Electrochemistry, 1974, 10(10), pp. 1555-1557 (in Russian).

12. Tarasevich, R.M. Electrochemistry of carbonic materials. Nauka: Moscow. 1984, 253 p. (in Russian).

13. Frumkin, A.N.; Bagotsky, V.S.; Iofa, Z.A.; et al. Kinetics of electrode processes. MSU: Moscow. 1952, 321 p. (in Russian).

14. Bagotsky, V.S. The bases of electrochemistry. Chemistry: Moscow. 1988, 400 p. (in Russian).

15. Beck, R.Yu. Perspectives of application of the electrodes with extended surface in hydrometallurgy. Proceedings of Siberian Branch of Academy of Sciences of USSR, Chemical Series, 1977, 6(4), pp. 11-20 (in Russian).

16. Jerebilov, A.F.; Varentsov, V.K. Experimental study of the polarization distribution along the depth of the flowthrough three-dimensional electrodes made of the carbonic fibrous materials on the metals electrodeposition. Proceedings of Siberian Branch of Academy of Sciences of USSR, Chemical Series, 1987, 1, pp.19-24 (in Russian).

17. Jerebilov, A.F.; Varentsov, V.K. Experimental prove of the anodic zones presence on the cathode made of the carbonic graphite fibrous materials. Proceedings of Siberian Branch of Academy of Sciences of USSR, Chemical Series, 1985, 3(8), pp. 35-39 (in Russian).

18. Varentsov, V.K. Electrolysis with the three-dimensional flow-through electrodes in the hydrometallurgy of noble metals. Proceedings of Siberian Branch of Academy of Sciences of USSR, Chemical Series, 1984, 6(17), pp. 106-120 (in Russian). 